\title{
Willingness to Pay Pelayanan Konseling Apoteker di Apotek di Kecamatan Polokarto Tahun 2016
}

\section{Willingness to Pay for Pharmacist Counseling at Pharmacy in Polokarto Sub-district in 2016}

\author{
Mariska Sri Harlianti $^{1}$, Tri Murti Andayani², Diah Ayu Puspandari ${ }^{3}$ \\ ${ }^{1}$ Bagian Farmakologi dan Farmasi Klinis Universitas Muhammadiyah Surakarta, Indonesia \\ ${ }^{2}$ Fakultas Farmasi Universitas Gadjah Mada Yogyakarta, Indonesia \\ ${ }^{3}$ Fakultas Kedokteran Universitas Gadjah Mada Yogyakarta, Indonesia \\ *email: mariska@ums.ac.id
}

\begin{abstract}
Abstrak
Konseling merupakan salah satu bagian dalam pelayanan farmasi klinik di apotek yang menjadi tanggung jawab apoteker untuk mencapai tujuan terapi. Kebutuhan masyarakat terhadap konseling mengalami peningkatan sehingga diperlukan peran serta aktif apoteker melalui pemberian jasa profesi. Penelitian ini perlu dilakukan untuk mengetahui besaran jasa pelayanan konseling oleh apoteker yang bersedia dibayarkan oleh pasien dengan parameter nilai WTP (Willingness to Pay). Selain itu, nilai WTP juga dapat menggambarkan benefit tidak langsung yang dirasakan masyarakat terhadap pelayanan konseling oleh apoteker di apotek. Penelitian ini merupakan penelitian deskriptif observasional melalui survei. Penelitian dilakukan di 3 apotek di kecamatan Polokarto Kabupaten Sukoharjo pada bulan Januari - Februari 2016 dengan responden pengunjung apotek yang mendapatkan pelayanan konseling oleh apoteker. Sebanyak 82 pasien berpartisipasi dalam penelitian ini. Besarnya nilai WTP ditentukan berdasarkan rata-rata nilai WTP yang dipilih oleh pasien dengan metode payment card. Hasil penelitian menunjukkan bahwa rata-rata nilai WTP pelayanan konseling apoteker di 3 apotek di wilayah kecamatan Polokarto adalah Rp. $15.892 \pm 8.533$. Kata kunci: willingness to pay, kesediaan membayar, konseling apoteker, tarif konseling.
\end{abstract}

\begin{abstract}
Counseling is one part of the clinical pharmacy service at the pharmacy that is the responsibility of the pharmacist to achieve therapeutic goal. Community needs for counseling have increased so that the active participation of pharmacists is needed through the provision of professional services. This research needs to be done to find out the amount of counseling services by pharmacists who are willing to be paid by patients with a WTP (Willingness to Pay) value parameter. In addition, the value of WTP can also describe the indirect benefits felt by the community towards counseling services by pharmacists at the pharmacy. This research is a descriptive observational research through a survey. The study was conducted at the pharmacy in the Polokarto sub-district of Sukoharjo regency in January - February 2016 with pharmacy visitor respondents who received counseling services by pharmacists. A total of 82 patients participated in this study. The amount of WTP is determined based on the average WTP value chosen by the patients with the payment card method. The result showed that the average WTP value of pharmacist counseling services at pharmacies in Sukoharjo regency was Rp. 15,892.
\end{abstract}

Keywords: willingness to pay, pharmacist's counseling service, pharmacist' counseling rates.

\section{PENDAHULUAN}

Informasi obat dan konseling merupakan komponen pharmaceutical care (Handayani et al., 2009) yang wajib diberikan oleh apoteker di apotek ketika menyerahkan obat kepada pasien. Informasi tersebut berkaitan dengan penggunaan obat secara tepat, aman dan rasional (Hartini et al., 2010). Kebutuhan masyarakat mengenai informasi obat dan konseling meningkat tetapi memberikan sikap negatif ketika informasi obat dan konseling dilakukan di depan counter serta ada jasa yang harus diberikan kepada apoteker (Abdullah et al., 2010). Selain itu, 
pelaksanaan proses konseling di apotek belum berjalan sebagaimana mestinya. Di Kabupaten Sleman dan Kota Yogyakarta, komponen pemberian informasi obat kepada pasien yang disertai dengan jadwal konseling oleh apoteker baru dilakukan oleh 34\% apotek (Hartini et al., 2010). Penelitian yang dilakukan oleh Herman and Susyanty (2012) menunjukkan bahwa konseling, informasi dan edukasi banyak dilakukan oleh asisten apoteker. Hal tersebut merupakan tantangan bagi apoteker agar dapat memberikan pelayanan sesuai dengan standar pelaksanaan dan peraturan perundang-undangan yang berlaku.

Salah satu upaya untuk meningkatkan pelaksanaan standar pelayanan kefarmasian adalah menentukan besarnya tarif jasa pelayanan, terutama pemberian informasi obat melalui proses konseling. Kompensasi finansial merupakan salah satu aspek dalam Quality of Work Life (QWL) (Indrani and Devi, 2014). Benefit yang diperoleh jika QWL tercapai dengan baik antara lain: meningkatkan keterlibatan dalam pekerjaan, kepuasan dan produktivitas kerja (Garg, et al., 2012). Willingness to pay (WTP) merupakan salah satu metode untuk mengetahui preferensi seseorang terhadap kualitas pelayanan. Besaran mata uang dalam WTP tidak hanya menggambarkan harga tetapi juga menunjukkan nilai suatu barang atau jasa yang dinyatakan berdasarkan preferensi seseorang. Ketika seseorang bersedia membayar dengan harga yang rendah, berarti preferensinya terhadap nilai suatu barang atau jasa tersebut juga rendah (Grigorov et al., 2012) atau bahkan tidak membutuhkannya sehingga permintaan (demand) akan menurun (Freeman et al., 2014). Penelitian ini dilakukan untuk mengetahui kemauan membayar masyarakat terhadap pelayanan konseling apoteker di apotek sehingga dapat memberikan informasi kepada organisasi profesi kisaran tarif pelayanan konseling yang nantinya akan ditetapkan. Selain itu, perlu dikaji faktor apa saja yang berpengaruh terhadap nilai WTP tersebut sehingga dapat dilakukan penyesuaian tarif.

\section{METODOLOGI PENELITIAN}

Penelitian ini merupakan penelitian deskriptif observasional melalui survei dengan. Pengunjung apotek yang bersedia berpartisipasi dalam penelitian ini sebanyak 82 orang dari 3 apotek di kecamatan Polokarto. Sampling dilakukan menggunakan metode non probability sampling yaitu purposive sampling. Jumlah apotek yang bersedia ikut serta dalam penelitian ini belum dapat mewakili populasi apotek di kecamatan Polokarto dikarenakan keterbatasan peneliti. Nilai WTP ditentukan berdasarkan nilai ratarata WTP responden yang bersedia membayar jasa pelayanan konseling apoteker di apotek berdasarkan data yang diperoleh dari payment card.

\section{HASIL DAN PEMBAHASAN}

Pada penelitian ini, sebanyak 56 responden menyatakan bersedia membayar jasa pelayanan konseling oleh apoteker di apotek dengan nilai rata-rata Rp. $15.892 \pm$ 8.533. Berdasarkan Tabel 1, lebih dari 50\% responden memilih Rp. 10.000;, dimana pilihan tersebut merupakan nilai yang paling rendah. Sedangkan Rp. 35.000; sebagai nilai tertinggi, dipilih oleh $12,5 \%$ responden.

Tabel 1. Frekuensi nilai WTP pelayanan konseling apoteker di 3 apotek di kecamatan Polokarto tahun $2016(n=56)$

\begin{tabular}{cc}
\hline $\begin{array}{c}\text { WTP } \\
\text { (Rupiah) }\end{array}$ & $\mathrm{n}(\%)$ \\
\hline 10.000 & $30(53,6)$ \\
15.000 & $11(19,7)$ \\
20.000 & $4(7,1)$ \\
25.000 & $4(7,1)$ \\
30.000 & $0(0)$ \\
35.000 & $7(12,5)$ \\
\hline
\end{tabular}


Tabel 2. Distribusi kesediaan membayar dan rata-rata WTP (Rupiah) pelayanan konseling oleh apoteker di 3 apotek di kecamatan Polokarto tahun 2016 berdasarkan demografi responden

\begin{tabular}{|c|c|c|c|c|c|}
\hline \multirow[t]{2}{*}{ Variabel } & \multicolumn{2}{|c|}{$\begin{array}{l}\text { Tidak Bersedia } \\
\quad(\mathrm{n}=26)\end{array}$} & \multicolumn{2}{|c|}{$\begin{array}{c}\text { Bersedia } \\
(\mathrm{n}=56)\end{array}$} & \multirow{2}{*}{$\begin{array}{c}\text { Rata-rata WTP } \\
\text { (Rupiah) }\end{array}$} \\
\hline & $\mathrm{n}$ & $\%$ & $\mathrm{n}$ & $\%$ & \\
\hline \multicolumn{6}{|l|}{ Usia } \\
\hline $18-27$ tahun & 2 & 7,70 & 12 & 21,43 & 11.250 \\
\hline $28-37$ tahun & 9 & 34,62 & 7 & 12,50 & 22.143 \\
\hline $38-47$ tahun & 7 & 26,92 & 12 & 21,43 & 18.333 \\
\hline $48-57$ tahun & 4 & 15,38 & 18 & 32,14 & 12.500 \\
\hline $58-67$ tahun & 4 & 15,38 & 5 & 8,93 & 17.000 \\
\hline $68-77$ tahun & 0 & 0 & 2 & 3,57 & 35.000 \\
\hline \multicolumn{6}{|l|}{ Jenis kelamin } \\
\hline Laki-laki & 19 & 73,08 & 17 & 30,36 & 15.000 \\
\hline Perempuan & 7 & 26,92 & 39 & 69,64 & 16.282 \\
\hline \multicolumn{6}{|l|}{ Pendidikan } \\
\hline SD & 0 & 0 & 0 & 0 & 0 \\
\hline SMP & 3 & 11,54 & 12 & 21,43 & 14.583 \\
\hline SMA / D3 & 8 & 30,77 & 12 & 21,43 & 19.583 \\
\hline Sarjana (S1 / S2) & 15 & 57,69 & 32 & 57,14 & 15.000 \\
\hline \multicolumn{6}{|c|}{ Penghasilan per bulan } \\
\hline$<1$ juta & 2 & 7,70 & 11 & 19,64 & 15.000 \\
\hline $1-2$ juta & 6 & 23,08 & 6 & 10,71 & 16.667 \\
\hline $2-3$ juta & 5 & 19,22 & 17 & 30,36 & 18.824 \\
\hline $3-4$ juta & 4 & 15,38 & 12 & 21,43 & 14.583 \\
\hline $4-5$ juta & 7 & 26,92 & 10 & 17,86 & 13.000 \\
\hline $5-6$ juta & 2 & 7,70 & 0 & 0 & 0 \\
\hline \multicolumn{6}{|l|}{ Penyakit kronis } \\
\hline Ada & 2 & 7,70 & 31 & 55,36 & 20.161 \\
\hline Tidak ada & 24 & 92,30 & 25 & 44,64 & 10.600 \\
\hline \multicolumn{6}{|c|}{ Jumlah konseling per bulan } \\
\hline $1-2 \mathrm{x}$ & 26 & 100 & 51 & 91,07 & 14.902 \\
\hline $3-4 x$ & 0 & 0 & 5 & 8,93 & 26.000 \\
\hline
\end{tabular}

Responden yang tidak bersedia membayar, sebagian besar berusia $28-37$ tahun, laki-laki, sarjana, penghasilan per bulan $4-5$ juta rupiah, tidak menderita penyakit kronis dan pernah konseling dengan apoteker sebanyak $1-2 \mathrm{x}$ per bulan. Data tersebut disajikan dalam Tabel 2.

Adanya responden yang bersedia membayar jasa pelayanan konseling oleh apoteker di apotek menunjukkan bahwa konseling memiliki nilai dan dibutuhkan oleh masyarakat. Konseling yang efektif mampu meningkatkan kepatuhan, memotivasi pasien untuk ikut ambil bagian dalam kesehatannya (Terrie, 2008) serta meningkatkan cost effectiveness (Mashuda, 2011). Dari sudut pandang Jaminan Kesehatan Nasional (JKN), hal tersebut dapat mengurangi beban JKN karena angka rawat inap dapat ditekan sehingga biaya yang dikeluarkan lebih sedikit.

Berdasarkan data rata-rata penghasilan per bulan, responden mempunyai kemampuan membayar, Ability to Pay, 
(ATP) sebesar Rp. 40.000; - Rp. 60.000; (2\% $\mathrm{x}$ rata-rata pendapatan per bulan). Tetapi nilai rata-rata WTP pada penelitian ini adalah Rp. 15.892;, lebih rendah dibandingkan nilai ATP. Hal ini menunjukkan bahwa sebenarnya masyarakat mampu tetapi tidak mau membayar dengan nilai yang sama. Menurut Juliasih and Hardy (2013) hal tersebut disebabkan kurangnya utilitas jasa pelayanan bagi pasien. Selama ini, masyarakat telah menggunakan obat di apotek tanpa proses konseling yang memadai. Masyarakat dapat menggunakan obat tanpa kendala yang berarti sehingga adanya praktek konseling yang marak beberapa waktu ini tidak terlalu berpengaruh bagi masyarakat.

Apoteker perlu melakukan pendekatan lebih jauh lagi kepada masyarakat untuk menunjukkan pentingnya konseling dalam penggunaan obat. Apoteker harus menunjukkan jati dirinya dalam masyarakat. Ikatan Apoteker Indonesia sebagai organisasi profesi apoteker telah mempunyai beberapa program agar apoteker dapat dihargai oleh masyarakat sebagai profesi yang mampu bekerja secara professional. Program resertifikasi kompetensi apoteker merupakan salah satu cara agar apoteker seluruh Indonesia dapat menjalankan praktek kefarmasian, salah satunya adalah konseling di apotek. Apoteker dibekali dengan ilmu pengetahuan dan ketrampilan yang memadai. Sehingga masyarakat dapat merasakan pengaruh positif konseling oleh apoteker di apotek. Di sisi lain, apoteker sebagai profesi yang bertanggungjawab terhadap obat dan pengobatan mampu menunjukkan kinerja profesionalnya sesuai dengan perundangundangan yang berlaku.

Kajian yang dilakukan oleh Freeman et al. (2014) menyebutkan bahwa ada beberapa alasan seseorang tidak mau membayar jasa atas suatu pelayanan, yaitu: keuangan, pengalaman mendapatkan pelayanan dan kebutuhan akan pelayanan. Jasa pelayanan yang harus dibayar oleh masyarakat dengan harga tinggi akan meningkatkan keengganan untuk membayar. Masyarakat yang sudah pernah mendapatkan suatu pelayanan akan enggan membayar untuk pelayanan yang sama, apalagi dengan kualitas yang kurang baik. Faktor kebutuhan akan pelayanan sangat berpengaruh terhadap keengganan masyarakat untuk membayar. Untuk meningkatkan kesediaan membayar masyarakat atas suatu pelayanan perlu dilakukan edukasi dan sosialisasi yang intensif serta peningkatan kualitas pelayanan. Peneliti tidak dapat mengkaji alasan responden yang tidak mau membayar disebabkan tidak ada terkait hal tersebut dalam pengambilan data.

\section{KESIMPULAN}

Willingness to pay pelayanan konseling apoteker di 3 apotek di kecamatan Polokarto adalah Rp. $15.892 \pm 8.533$;

\section{UCAPAN TERIMA KASIH}

Peneliti mengucapkan terima kasih kepada Dirjen Dikti atas beasiswa pendidikan yang diberikan (BPPDN).

\section{DAFTAR PUSTAKA}

Abdullah, N.A., Andrajati, R., Supardi, S., 2010. Pengetahuan, Sikap dan Kebutuhan Pengunjung Apotek terhadap Informasi Obat di Kota Depok. Buletin Penelitian Sistem Kesehatan. 13, $344-352$.

Dewi, R., 2005. Analisis Kemauan Membayar Pasien (WTP) dihubungkan dengan Karakteristik Kemampuan Membayar (ATP) dan Persepsi Pasien terhadap Mutu dan Manfaat Pelayanan di Puskesmas Sukmajaya Depok, Tesis, Fakultas Kesehatan Masyarakat Universitas Indonesia, Jakarta. 
Freeman, P.R., Jones, M., Blumenschein, K., 2014. It's Not Just the Money : Why Consumers Do Not Purchase Pharmacist Provide Services. Pharmacology and Pharmacy. 570 576. doi:10.4236/pp.2014.56067

Grigorov, E.E., Naseva, E.K., Lebanova, H.V., Getov, I.N., 2012. Testing Willingness to Pay for Blood Pressure Measurement in Community Pharmacy. African Journal of Pharmacy and Pharmacology. 6, 1005 - 1010. doi:10.5897/AJPP12.047

Handayani, E., Gondodiputro, S., Saefullah, A., 2013. Faktor-Faktor yang Mempengaruhi Kemauan Masyarakat Membayar Iuran Jaminan Kesehatan di Kabupaten Hulu Sungai Selatan.

Hartini, Y.S., Sulasmono, Sukmajati, M., Kurniawan, A., 2010. Pelaksanaan Standar Pelayanan Kefarmasian di Apotek di Sleman dan Yogyakarta, http://www.ikatanapotekerindonesia.net/news/pharma-update/pelaksanaan-standarpelayanan-kefarmasian-di-apotek-di-sleman-dan-yogyakarta

Hendriyanto, 2009. Faktor-Faktor yang Mempengaruhi Kemauan Membayar Pasien Instalasi Rawat Jalan RSD Ciawi Kabupaten Bogor Tahun 2009, Tesis, Fakultas Kesehatan Masyarakat Universitas Indonesia, Jakarta.

Herman, M.J., Susyanty, A.L., 2012. An Analysis of Pharmacy Services by Pharmacist in Community Pharmacy. Buletin Penelitian Sistem Kesehatan. 15, 271 - 281.

Juliasih, I.G.A., Hardy, P.D.K., 2013. Analisis Kemampuan dan Kemauan Membayar Pasien Rawat inap di Rumah Sakit Umum Daerah Karangasem Tahun 2013. Community Health (Bristol) I, $151-161$.

Mashuda, A., 2011. Pedoman Cara Pelayanan Kefarmasian yang Baik (CPFB). Kementrian Kesehatan Republik Indonesia, Jakarta.

Mushunje, I.T., 2012. Willingness to Pay for Pharmacist-Provided Services Directed Towards Reducing Risks of Medication-Related Problems, Thesis, Nelson Mandela Metropolitan University, Port Elizabeth South Africa.

Terrie, Y.C., 2008. 10 Behaviours of Effective Counselors, http://www.pharmacytimes.com/publications/issue/2008/2008-05/2008-05-8527 